\title{
Renewable pine cone biomass derived carbon materials for supercapacitor
} application

\author{
Abdulhakeem Bello, Ncholu Manyala*, Farshad Barzegar, Abubakar A. Khaleed, Damilola Y. \\ Momodu and Julien K. Dangbegnon \\ Department of Physics, Institute of Applied Materials, SARCHI Chair in Carbon Technology and Materials, University \\ of Pretoria, Pretoria 0028, South Africa. \\ Corresponding author: Ncholu Manyala Email address: ncholu.manyala@up.ac.za
}

\begin{abstract}
The environmental degradation and hazard to human life caused by the depletion of fossils fuels and the urgent need for sustainable energy sources to meet the rising demand in energy has led to the exploration of novel materials that are environmentally friendly, low cost and less hazardous to human life for energy storage application using the green chemistry approach. Herein, we report on the transformation of the readily abundant pine cone biomass into porous carbon via $\mathrm{KOH}$ activation and carbonization at $800{ }^{\circ} \mathrm{C}$ as electrode materials supercapacitor. The porous carbon material exhibited a mesoporous framework with a specific surface area of $1515 \mathrm{~m}^{2} \mathrm{~g}^{-1}$, a high voltage window of $2.0 \mathrm{~V}$, a gravimetric capacitance of $137 \mathrm{~F} \mathrm{~g}^{-1}$, energy density of $19 \mathrm{Wh} \mathrm{kg}^{-1}$ and excellent cyclability in neutral $1 \mathrm{M} \mathrm{Na}_{2} \mathrm{SO}_{4}$ electrolyte for a symmetric
\end{abstract}


carbon/carbon electrodes cell. The result shows that the material is robust and shows the great promise of neutral electrolytes in high-performance energy-storage devices.

Keywords: Biomass, pine cones, microporous carbon, aqueous electrolyte, supercapacitors, electrochemical Properties

\section{Introduction}

Energy is crucial and a driving factor for the development of our society; technologically and socio-economically. The recent boom in energy demands from the energy sector due to increase in world population has led to the depletion of fossil fuels worldwide. Furthermore, the consumption of these fossil fuels is linked to environmental degradation that endangers human life, through climate changes and emission of greenhouse gas which often lead to high managements cost. Hence, there is a need for a paradigm shift from fossil fuels for the production of carbon materials for energy to a green and low-cost materials, to meet the increasing energy demand for sustainable and economic development ${ }^{1,2}$. In this regard, it is necessary to look for materials that are abundant, renewable and sustainable sources for energy applications. Biomass is a viable renewable source of carbon materials (solid, liquid or gaseous product) for energy applications and currently supplies about $14 \%$ of the world's energy due to the fact that they are readily available, low cost, regenerate rapidly, and are friendly and less harmful to the environment when compared with the fossil fuels ${ }^{3-7}$.

In order to meet and address the challenges of increasing demands, there has been a significant interest in the development of new, versatile, and scalable energy storage technology systems. 
Amongst these systems, electrochemical double layer capacitors (EDLCs also known as supercapacitors) are attractive and their energy storage mechanism is based on electrical double layer charge accumulation at the interface between the electrode and electrolyte. They hold a considerable promise for a wide range of applications, including portable electronic equipment's, regenerative breaking systems, uninterruptable power sources, load leveling and hybrid electric vehicles, and so forth due to theirs high power density, fast charging-discharging mechanism and excellent long life cycle ${ }^{8,9}$. Generally, the design and the electrochemical performance of EDLC are mainly dependent on the development of cost-effective electrode materials with a good representation of the pore structure and morphology. Carbonaceous materials are the most widely studied supercapacitor electrode active substances. They have been shown to have reasonable electrochemical performances, long-term cyclability and good electrochemical stability which are related to electronic conductivity and high specific surface area (SSA). While the most commonly used carbon material in the commercial industry is the activated carbon ${ }^{10}$. Other nanostructured forms of carbon such as carbon nanotubes (CNTs) ${ }^{11,12}$, carbide-derived carbons (CDCs) ${ }^{13,14}$, onion-like carbons (OLCs) ${ }^{15,16}$ and graphene ${ }^{17,18}$ are also explored as electrode materials for the next generation of EDLCs. Nevertheless, the energy density of EDLCs made from these materials is still small $\left(<10 \mathrm{Wh} \mathrm{kg}^{-1}\right)$ when compared to their battery counterparts ${ }^{19}$. Hence, all research activities and effort are aimed at improving on the properties of EDLCs either by increasing the capacity of the EDLC electrodes by modifying the carbon materials with different functionalities ${ }^{20,9}$ or by increasing the operating potential window since the energy density of an EDLC device is directly proportional to its capacity and also the square of its operating potential window. Recently, significant progress has been made 
in utilizing sustainable biomass for various applications. For example the production of carbon materials from organic waste for energy and absorbents applications has received much attention due to the environmental and degradation effect associated with the depletion of fossil fuels as mentioned earlier ${ }^{21,22}$. The natural, agricultural and organic wastes such as egg shell ${ }^{23}$, seaweeds ${ }^{24}$, dead leaves ${ }^{21}$, hemp basts ${ }^{25}$, wood sawdust ${ }^{26}$, yeast cells ${ }^{27}$, pistachio nutshells ${ }^{28}$, cigarette filter ${ }^{29}$, sunflower seed shell ${ }^{30}$, cypress ${ }^{31}$ and rice husk ${ }^{32}$ have all been explored as bio-source carbon using different synthesis methods including; hydrothermal ${ }^{26}$, direct pyrolysis ${ }^{24}$, chemical vapor deposition (CVD) ${ }^{33}$, gas-solid displacement reactions ${ }^{34}$, and wet chemistry techniques, such as sol-gel processes ${ }^{35}$. Recently human hair was carbonized at $800{ }^{\circ} \mathrm{C}$ and tested as electrode for EDLCs, the device fabricated exhibited with a specific capacitance of $340 \mathrm{~F} \mathrm{~g}^{-1}$ and $126 \mathrm{~F} \mathrm{~g}^{-1}$ both in $6 \mathrm{M} \mathrm{KOH}$ and $1 \mathrm{M} \mathrm{LiPF}_{6}$ ethylene carbonate/diethyl carbonate (EC/DEC) organic electrolyte, respectively, at a current density of 1 $\mathrm{A} \mathrm{g}^{-1}$ with good stability over 20000 cycles $^{36}$. Microporous carbon with a high surface area of about $1230 \mathrm{~m}^{2} \mathrm{~g}^{-1}$ synthesized by single-step pyrolysis of dead plant leaves also exhibited a very high specific capacitance of $400 \mathrm{~F} \mathrm{~g}^{-1}$ and an energy density of $55 \mathrm{Wh} \mathrm{kg}^{-1}$ at a current density of $0.5 \mathrm{~A} \mathrm{~g}^{-1}$ in aqueous $1 \mathrm{M} \mathrm{H}_{2} \mathrm{SO}_{4}{ }^{21}$ and symmetric capacitors built from seaweeds which was pyrolysed at $600{ }^{\circ} \mathrm{C}$ exhibited a potential window up to $1.6 \mathrm{~V}$ with excellent cycle life showing very small capacitance drop after 10,000 cycles ${ }^{20}$. Aside from the structural properties of these carbon materials, they are sustainable, low cost and pose no threat to the environment.

As a potential carbon sources, pine cones are common biomass waste which are abundant and widely available. Pines are coniferous trees in the genus Pinus family of the Pinaceae which arise in a wide range of environmental conditions. It sprouts up to $50 \mathrm{~m}$ in height with dark 
green needles and 5-10 cm length cones with rounded scales. Substantial amount of cones are produced yearly throughout the world, especially in pine plantations grown for the pulp and paper industry. They are mainly composed of cellulose, lignin and resins that contain a variety of organic compounds ${ }^{37,38}$. Porous carbon from pine cone biomass have been extensively studied as biosorbent for metal, dye waste waters, nitrate uptake and removal of lead (II) ions from aqueous solutions by adsorption ${ }^{39-42}$. There are very few reports on the use of pine cone derived carbons for energy storage applications. For example, Karthikeyan K. et. al. ${ }^{43}$ reported very high surface area activated carbons synthesized from pine cone petals. A symmetric supercapacitor fabricated from the produced carbon exhibited very high energy density of 61 Wh kg-1 and excellent stability in 1M LiPF6 in ethylene carbonate/dimethyl carbonate.

Similar, microporous carbon were derived from pinecone hull and tested as anode material for lithium batteries, which retained a discharge capacity of $357 \mathrm{~mA} \mathrm{~h} \mathrm{~g}^{-1}$, and a coulombic efficiency of $98.9 \%$ current density of $10 \mathrm{~mA} \mathrm{~g}^{-1} 44$. In this report we demonstrate the production of porous carbon materials via hydrothermal treatment, $\mathrm{KOH}$ activation and carbonization of pine cones and present the electrochemical performance of symmetric capacitors with this carbon material in $\mathrm{Na}_{2} \mathrm{SO}_{4}$ aqueous electrolyte. A detailed analysis of the electrodes in both three- and two setups show that a voltage window of ( $2 \mathrm{~V})$ can be obtained for a symmetric carbon/carbon capacitor operating in $1 \mathrm{M} \mathrm{Na}_{2} \mathrm{SO}_{4}$ aqueous electrolyte. The pine carbon materials were stable within this potential and showed no environmental issue like corrosion. The choice of $\mathrm{KOH}$ as activating reagent is based on the fact that it induces welldefined micropore size distribution at lower activation temperature and high yields in carbon materials ${ }^{45}$. The formation mechanism of porous carbons with $\mathrm{KOH}$ is attributed to carbon 
gasification by the removal of $\mathrm{CO}_{2}$ and to the presence of oxygen material present in the matrix. During the activation process, $\mathrm{CO}_{2}$ formed from $\mathrm{K}_{2} \mathrm{CO}_{3}$ in the annealing process is released and becomes significant at high temperatures. The released $\mathrm{CO}_{2}$ then react with hydrochar material from the pine to open up closed pores and enlarge existing micropores. On the other hand, the potassium-containing compounds, such as $\mathrm{K}_{2} \mathrm{O}$ and $\mathrm{K}_{2} \mathrm{CO}_{3}$, can be reduced by carbon to form $\mathrm{K}$

metal, thus causing the carbon gasification and hence the formation of pores ${ }^{45}$. The activation process takes places according to the following reaction ${ }^{45}$;

$6 \mathrm{KOH}+\mathrm{C} \leftrightarrow 2 \mathrm{~K}+3 \mathrm{H}_{2}+2 \mathrm{~K}_{2} \mathrm{CO}_{3}$

\section{Experimental}

\section{Synthesis of activated pine carbon (APC).}

The readily available pine cones (PC) collected from the University of Pretoria campus Hatfield, South Africa were used as raw materials. The cones were washed repeatedly with acetone and distilled water to remove adhering dirt and soluble impurities and dried at $60^{\circ} \mathrm{C}$. After drying, the cleaned PC was crushed to powder using a swing mill equipped with a tungsten carbide port and $8 \mathrm{~g}$ of the PC powder was then dispersed in $80 \mathrm{ml}$ of distilled water containing $0.5 \mathrm{ml}$ of sulphuric acid. The disperse was transferred into a stainless steel autoclave and was heated up to $160{ }^{\circ} \mathrm{C}$ for $12 \mathrm{~h}$ and then allowed to cool to room temperature. The resulting solid black product was filtered and washed with distilled water and dried overnight at $80{ }^{\circ} \mathrm{C}$. The dried solid black product was activated by mixing with $\mathrm{KOH}$ with a 1:1 mass ratio in agate mortar. The mixture was then placed in a horizontal tube furnace ramped from room temperature to $800{ }^{\circ} \mathrm{C}$ at $10{ }^{\circ} \mathrm{C} / \mathrm{min}$ under argon flow and kept at this temperature for $1 \mathrm{~h}$ for the carbonization 
process. The resulting dark solid material was washed with $0.1 \mathrm{M} \mathrm{HCl}$ solution, and then washed with distilled water until the neutral $\mathrm{pH}$ was obtained. The product was collected and dried at $80{ }^{\circ} \mathrm{C}$ in an electric oven. The resultant powder was denoted as activated pine carbon (APC). Scheme 1 shows the transformation of PC into porous carbons.

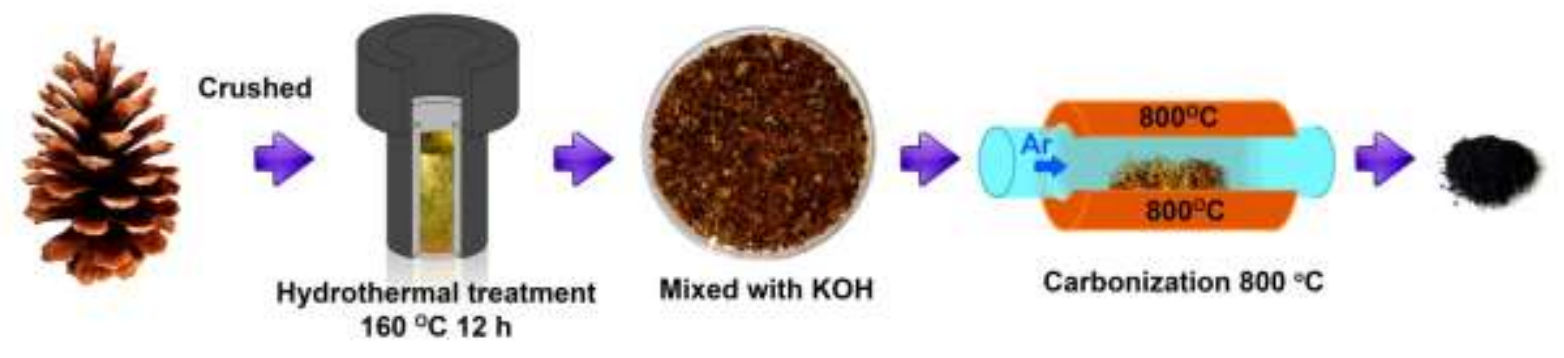

Scheme 1 Schematic diagram for the synthesis of porous carbons from pine cone

\section{Physico-chemical characterization of the APC}

Scanning electron microscopy (SEM) micrographs of the carbon were observed via Zeiss Ultra Plus 55 field emission scanning electron microscope (FE-SEM) operated at an accelerating voltage of $2.0 \mathrm{kV}$. Transmission electron microscopy (TEM) analysis was made at $200 \mathrm{kV}$ on a JEOL JEM-2100F microscope with field-emission gun. Typically, TEM samples were prepared by dispersing the samples in ethanol and dropped on lacey carbon grid for analysis. The surface area measurement of the sample was performed by liquid nitrogen cryosorption at $-196{ }^{\circ} \mathrm{C}$ using a surface area and pore size analyzer Micromeritics TriStar II 3020 (version 2.00). The samples were degassed at $150{ }^{\circ} \mathrm{C}$ for more than $12 \mathrm{~h}$ under vacuum conditions. The surface area was calculated by the Brunauer-Emmett-Teller (BET) method. X-ray photoelectron 
spectroscopy (XPS) was used to determine the chemistries of activated carbons in powder form. A Physical Electronics VersaProbe 5000 instrument was used employing a $100 \mu \mathrm{m}$ monochromatic Al-Ka to irradiate the sample surface. Photoelectrons were collected by a 180 은 hemispherical electron energy analyzer. Samples were analyzed at a $45^{\circ}$ angle between the sample surface and the path to the analyzer. Survey spectra were taken at pass energy of 117.5 $\mathrm{eV}$, with a step size of $0.1 \mathrm{eV}$, which was used to obtain the elemental analysis of the powders. High-resolution spectra of C1s, N1s, and O1s regions were taken at pass energy of $23.5 \mathrm{eV}$, with a step size of $0.05 \mathrm{eV}$. The spectra were taken after the samples were sputtered with an $\mathrm{Ar}$ beam operating at $2.0 \mathrm{kV}$ and $150 \mu \mathrm{A}$ for $10 \mathrm{~min}$. All binding energies were referenced to that of the binding energy of the Fermi level $\mathrm{E}_{\mathrm{f}}=0 \mathrm{eV}$. Peak fitting for the high-resolution spectra was performed using CasaXPS Version 2.3.16 RP 1.6. Prior to the peak fitting the background contributions were subtracted using a Shirley function. Raman analysis of the sample was recorded using a WiTec-alpha 300R+ confocal Raman spectrometer (WiTec GmbH) with the laser power of $1.5 \mathrm{~mW}$ in order to minimize heating effects. The excitation source was a 532$\mathrm{nm}$ laser through a numerical aperture of 0.9 and 100x magnification. FTIR spectra were recorded on a Vertex 70v (Bruker) spectrometer in the 4000-400 $\mathrm{cm}^{-1}$ range with $4 \mathrm{~cm}^{-1}$ resolution. Sample compartment was evacuated during acquisition. Spectra were recorded and analysed with the Opus software.

\section{Electrochemical measurements}

The electrochemical measurements were carried out on a multichannel VMP300 potentiostat/galvanostat (Bio-Logic, France) at room temperature. The working electrodes 
were prepared by mixing a paste containing $80 \mathrm{wt} \%$ APC material, $10 \mathrm{wt} \%$ poly(vinylidene fluoride) (PVDF) (in N-methylpyrrolidone) and $10 \mathrm{wt} \%$ carbon black coated on a nickel foam with a diameter of $16 \mathrm{~mm}$. Afterwards, the working electrode was pressed and dried in vacuum at $80{ }^{\circ} \mathrm{C}$ overnight in an electric oven to ensure complete evaporation of the NMP. Each electrode has a mass loading of about $2.5 \mathrm{mg}$. The electrochemical test of the APC electrode was performed in a three electrode configuration using glassy carbon plate as counter electrode and $\mathrm{Ag} / \mathrm{AgCl}\left(3 \mathrm{M} \mathrm{KCl}\right.$ ) as the reference electrode in $1 \mathrm{M} \mathrm{Na}_{2} \mathrm{SO}_{4}$ aqueous electrolyte. The symmetric devices were assembled such that two electrodes were separated by a $0.18 \mu \mathrm{m}$ thick microfiber glass filter paper in CR2025-type coin cells. The cyclic voltammetry and galvanostatic charge-discharge tests for these devices were recorded in a potential window from 0 to $2 \mathrm{~V}$ at various scan rates and current densities. Electrochemical impedance spectroscopy (EIS) measurements were conducted in a frequency range of $100 \mathrm{kHz}$ to $0.01 \mathrm{~Hz}$ with an open circuit voltage using a sinusoidal signal of $5 \mathrm{mV}$. The gravimetric capacitance for the single electrode was calculated according to ${ }^{46}$ :

$C(F / g)=\frac{4 I}{(d V / d t) m}$

where I is the current $(\mathrm{A}), d V / d t$ is the slope of the discharge curve $(\mathrm{V})$ of the cell excluding the IR drop during the discharge process and $\mathrm{m}$ is the mass of carbon in one electrode $(\mathrm{g})$. The factor of 4 accounts for the two electrode setup, where the charge is evenly distributed across two capacitors in series ${ }^{46}$. The energy density or maximum energy density $E(\mathrm{Wh} / \mathrm{kg})$, of the electrodes was estimated as

$\mathrm{E}(W h / k g)=\frac{1}{2} \mathrm{C} \Delta \mathrm{V}^{2}=\frac{1000 \times \mathrm{C} \times \Delta \mathrm{V}^{2}}{2 \times 4 \times 3600}=\frac{\mathrm{C} \times \Delta \mathrm{V}^{2}}{28.8}$ 
where $C$ is gravimetric capacitance of the electrode $(F / g)$ calculated from $C D$ curves at different current densities, $\Delta \mathrm{V}$ is the width of the voltage window $(\mathrm{V})$. The specific power density, $\mathrm{P}$ $(\mathrm{W} / \mathrm{kg})$, of the electrodes was calculated by dividing the electrode energy density by the discharge time (h) at different current densities.

$P=E / \Delta t$

The Coulombic efficiency ( $\varepsilon$ also referred to as Faradaic or current efficiency) values were calculated from the charge-discharge curve using the following equations

$\varepsilon=\frac{\Delta t_{\text {discharge }}}{\Delta t_{\text {charge }}} \times 100 \%$

where $\Delta t$ represent the charging and discharging time.

\section{Results and discussion}

Scanning electron microscopy (SEM) and transmission electron microscopy (TEM) were used to investigate the structure and morphology of the as-synthesized materials. Figure 1 (a) and (b) shows a low and high magnification SEM micrographs of the APC sample and it is clear from the figure that $\mathrm{KOH}$ activation process leads to the formation of porous cavities in the material as observed in Figure 1 (a). Higher magnification features the existence of ample amount of pores in the 3D interconnected that are linked together in the carbon frameworks with dimension from nanometers to several micrometres pores in the network. Transmission electron microscopy (TEM) micrographs, further highlights the structure of the produced carbon material. Figure 1 (c and d) show that the material consists of highly interconnected 3D hollow and porous spheres that overlap each other and some of the spheres are split open. The 
diameters of some of the spheres are in the range of 100-200 nm. This type of porous structure could be favourable for energy storage since it has been established that the porosity of the activated carbon materials governs its energy storage and power delivery capability ${ }^{47}$.
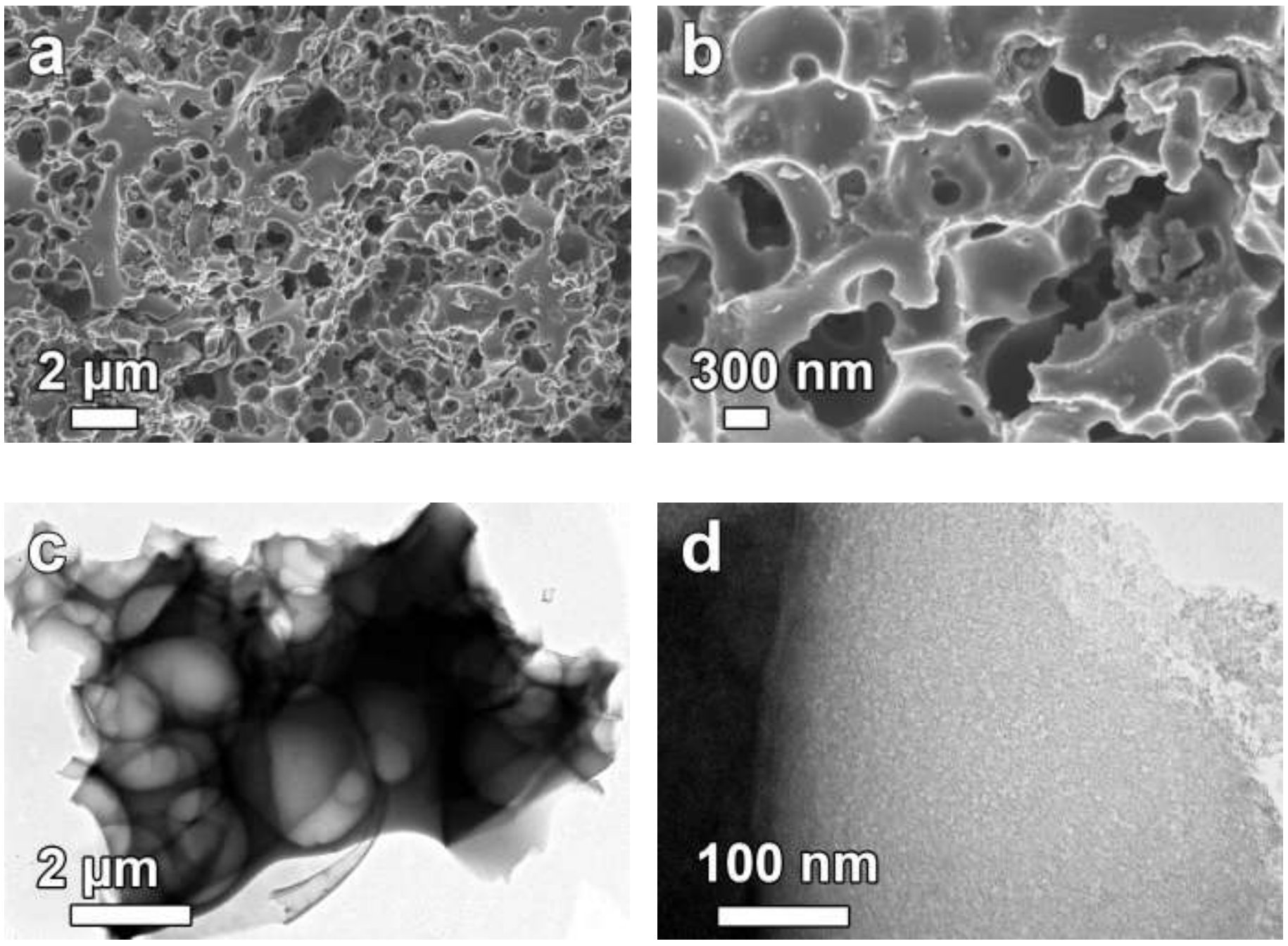

Figure 1 (a-b) SEM and (c-d) TEM micrographs of APC showing low and high magnification respectively

The pore texture of the APC material was analyzed by $\mathrm{N}_{2}$ adsorption/desorption measurements. Figure 2 show that APC exhibits a type-II behavior with a H4-type hysteresis 
suggesting a complex material containing both micropores and mesopores. The specific surface area (SSA) and the pore volume of the material are $1515 \mathrm{~m}^{2} \mathrm{~g}^{-1}$ and $0.38 \mathrm{~cm}^{3} \mathrm{~g}^{-1}$ respectively. The pore size distributions (inset to the figure) was calculated using the Barrett-Joyner-Halenda (BJH) analysis from the desorption branch and the pore size in the material is mainly distributed within 2-100 $\mathrm{nm}$ range. The higher surface area and narrower pore size distribution could be beneficial in charge storage by providing high adsorbate accessibility and providing wider transport channels to micropores ${ }^{48}$.

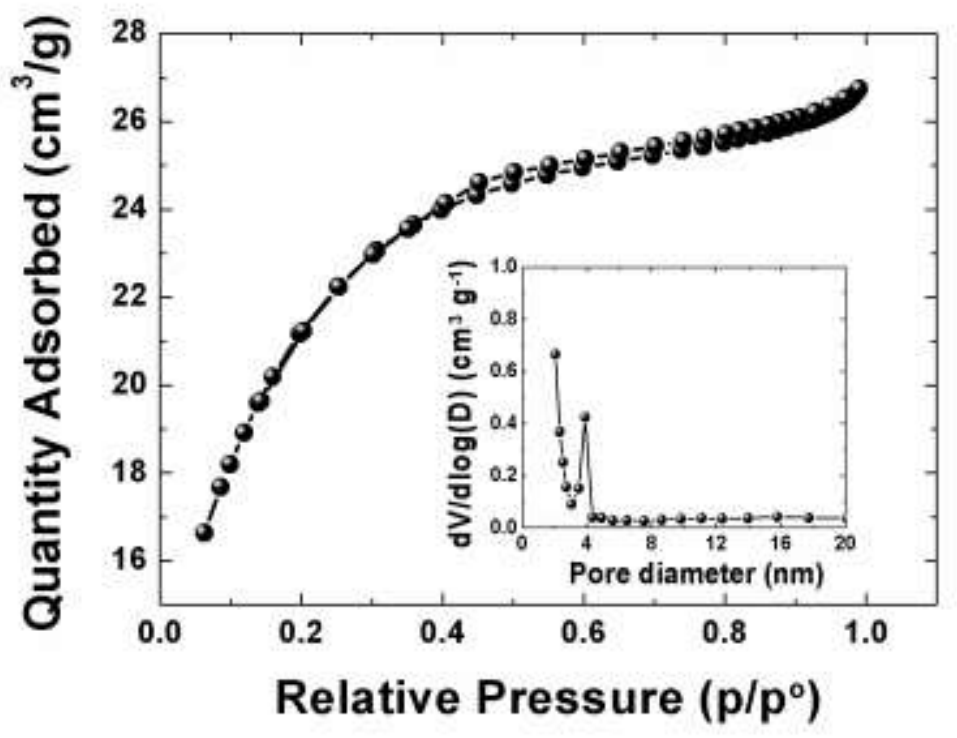

Figure $2 \mathrm{~N}_{2}$ adsorption/desorption isotherms of APC material, Inset show pore size distribution.

The elemental composition of the APC sample was obtained from XPS characterization of the survey spectra shown in table S1 (supporting information) and Figure 3. Carbon is considered to be the major element in the samples with a small amount of $\mathrm{K}, \mathrm{O}$ and $\mathrm{N}$ on the surface. The results of the peak fitting for the sample are shown in Figure 3 (a) and table $S 2$. The $C 1 s / K 2 p$ 
region was fitted by six components corresponding to graphitic carbon, hydrocarbons ( $\mathrm{CHx}$ ), alcoholic (C-O-) and/or carbon nitrogen structures (C-N-), carboxyl or ester (COO), and the $2 p 3 / 2$ and $2 p 1 / 2$ components arising from the $K 2 p$ region which might correspond to potassium oxide and/or hydroxide. The 01 s region Figure 3 (b) was fitted by three components corresponding to potassium oxide and/or hydroxide, $\mathrm{C}-\mathrm{O}$ - and $\mathrm{COO}$. However, the $\mathrm{N} 1 \mathrm{~s}$ peak was fitted with two components corresponding to pyridine and/or amine and nitrile and/or pyrrole Figure 3 (c).
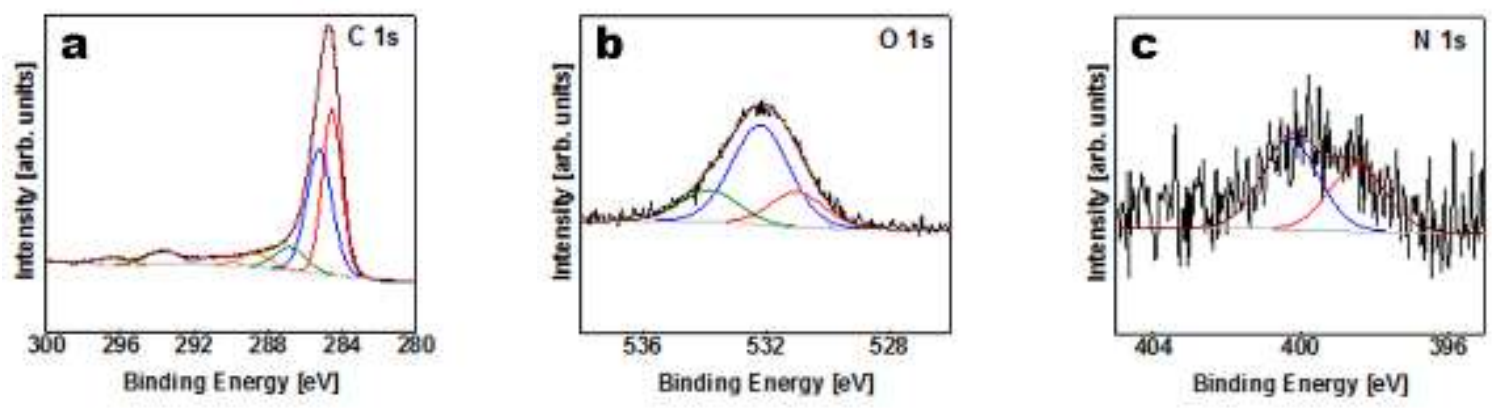

Figure 3 XPS spectra of $C 1 s, 0$ ss and N 1s regions for APC.

In order to further investigate the structure of this sample Raman analysis was also performed and it shown in Figure 4 (a). The Raman spectrum depicted in the figure shows the two prominent peaks located at $\sim 1342$ and $\sim 1587 \mathrm{~cm}^{-1}$ corresponding to $\mathrm{C}-\mathrm{C}$ graphitic lattice vibration mode with $A_{1 g}$ symmetry and known to be characteristics of disordered graphite structure defect D-band and G-band ( $\mathrm{sp}^{2}$-hybridized carbon) corresponds to an ideal graphitic lattice vibrational mode with $E_{2 G}$ symmetry, respectively ${ }^{49}$. The $I_{D} / I_{G}$ ratios were calculated from the $D$ and $G$ bands intensities is 0.99 indicating a low degree of graphitic crystalline structure. A Fourier transform infrared spectroscopy (FTIR) measurement was also used to 
probe the surface chemistry of the sample and, confirm the XPS results and is shown in Figure 4 (b). The spectra of the raw pine before, after hydrothermal treatment and after carbonization exhibits a broad absorption band at $~ 3000-3600 \mathrm{~cm}^{-1}$ with a maximum at $\sim 3354.9 \mathrm{~cm}^{-1}$ which is very pronounced after hydrothermal treatment and is assigned to $\mathrm{O}-\mathrm{H}$ stretching vibration of the surface hydroxyl groups, while the band at $\sim 2958.90 \mathrm{~cm}^{-1}$ before and after hydrothermal treatment shows the presence of aliphatic group $(\mathrm{C}-\mathrm{H})$ and the peak at $1647.1 \mathrm{~cm}^{-1}$ represents $\mathrm{C}=\mathrm{O}$ stretching vibrations of ketones, aldehydes, lactones or carboxyl groups. Peaks observed between 1100.8 and $559.3 \mathrm{~cm}^{-1}$ (after hydrothermal treatment) may be assigned to the $-\mathrm{C}-\mathrm{C}$ and $-\mathrm{CN}$ stretching ${ }^{42}$. The very weak band at $2650 \mathrm{~cm}^{-1}$ after carbonization represents the asymmetric vibration of $-\mathrm{CH}_{\mathrm{x}}$ hydrocarbon groups ${ }^{39}$. Disappearance of some peak after carbonization was observed. For example the band at $3354.9 \mathrm{~cm}^{-1}$ due to $(\mathrm{O}-\mathrm{H})$ stretching is no longer visible. This is due to the fact that high temperature carbonization could lead to the breaking of the bonds of the carboxylic groups and evaporate them as volatile matter.
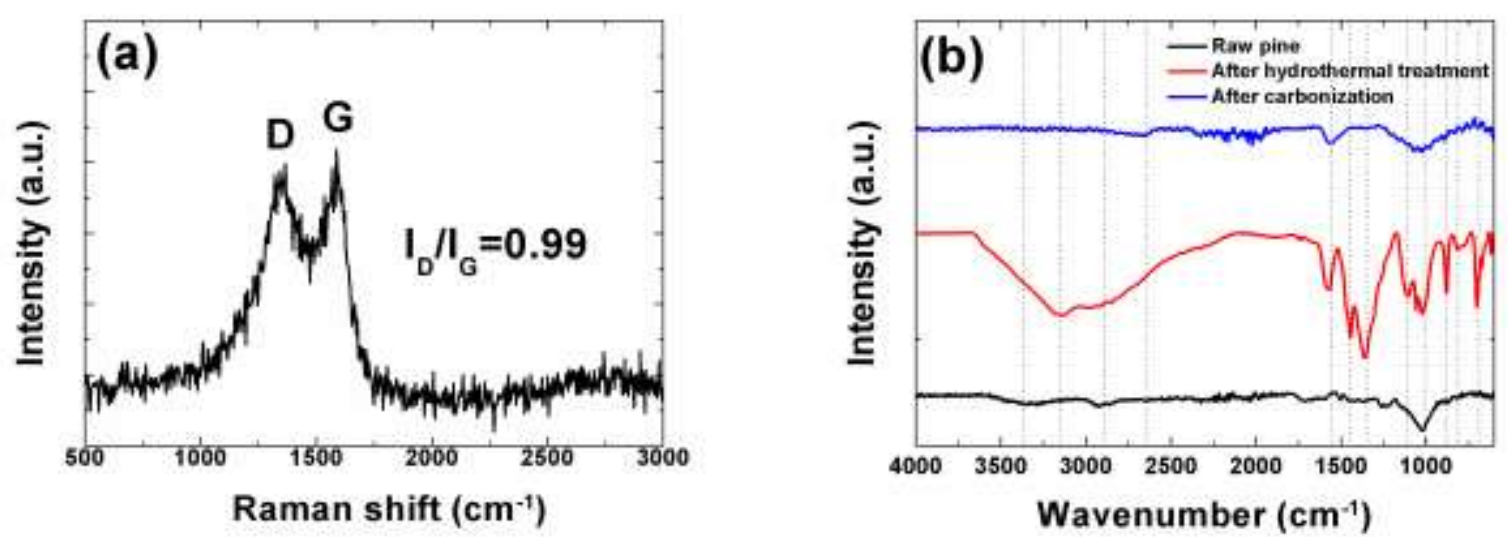

Figure 4 (a) Raman spectroscopy showing prominent D and G peaks and (b) FTIR spectra of raw, hydrothermal treated pine and the carbonized pine cone powder. 
The electrochemical behavior of the APC material was evaluated and the results are presented. Figure 5 present the cyclic voltammograms (CV) of the APC in a three electrode setup with a 1 $\mathrm{M} \mathrm{Na}_{2} \mathrm{SO}_{4}$ in the negative and positive potential window, with different potential ranging from $1 \mathrm{~V}$ to $1 \mathrm{~V}$. CV shapes are rectangular which indicating a very fast electrochemical response, confirming the good electrical conductivity for this material and demonstrate the formation of a double layer mechanism. The $\mathrm{CVs}$ are stable within this potential range and still within the thermodynamic stability window of water due to the increased electrolyte stable potential windows (ESPWs) when compared to both the acidic and alkaline aqueous electrolyte ${ }^{50}$. This large potential window is not surprising as it has been shown that neutral electrolyte can reach up to $2 \mathrm{~V}$ due to the fact that a neutral electrolyte has lower $\mathrm{H}^{+}$and $\mathrm{OH}^{-}$concentrations when compared to acidic and alkaline electrolytes, thus, a high over potential of for di-hydrogen evolution and oxygen evolution reactions can be expected which suggests an increase ESPW. The large potential is related with the storage of nascent hydrogen in the carbon material below the thermodynamic potential for water decomposition ${ }^{51,20}$. Below $-0.9 \mathrm{~V}$ and above 0.9 $V$ cathodic and anodic current leaps are observed which are indications of di-hydrogen and oxygen evolutions as the material approach $-1 \mathrm{~V}$ and $1 \mathrm{~V}$. 


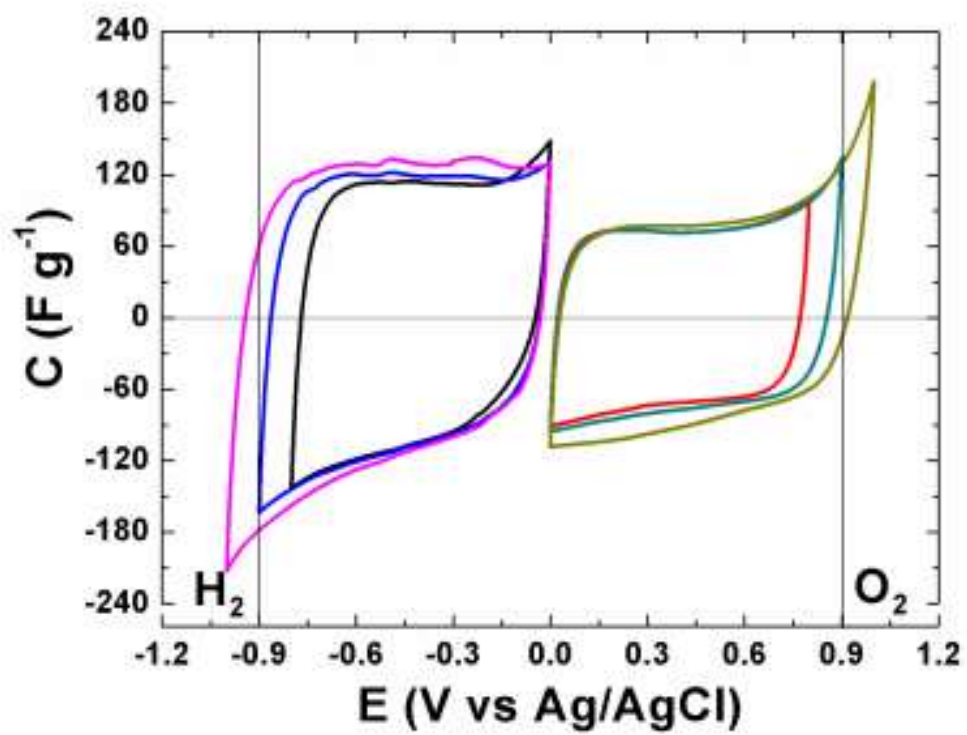

Figure $5 \mathrm{CVs}$ in a three electrode setup for the APC at $20 \mathrm{mV} \mathrm{s}^{-1}$ in $1 \mathrm{M} \mathrm{Na}_{2} \mathrm{SO}_{4}$ within negative and positive potential windows. The vertical lines represent the oxidation and reduction thermodynamic potential of water.

The CVs of a symmetric cell which combines both negative and positive potential window are shown in Figure 6 (a) from $1 \mathrm{~V}$ to $2 \mathrm{~V}$ potential ranges. At low voltage ranges the CVs show rectangular shapes which are characteristic of a pure EDLC behavior. With increasing voltage range the $\mathrm{CV}$ still maintains its symmetric rectangular shape with a slight increase in capacitance value. At the maximum potential window of $2.0 \mathrm{~V}$ a current leap is observed which could be due to the evolution of gases or oxygenated surface functionalities generated from both the positive and/or negative electrode and the reactions with the electrolyte ${ }^{19,51}$. The constant current charge-discharge (CD) was also measured at different voltage ranges and is presented in Figure 6 (b). The symmetrical triangular shape of the CD corroborates the formation of a double layer capacitor. The CD curves measurement show that the APC 
electrode material is stable at the maximum potential limit of $2 \mathrm{~V}$ without any distortion to the $\mathrm{CD}$, hence further measurements were made at potential window of $2 \mathrm{~V}$.
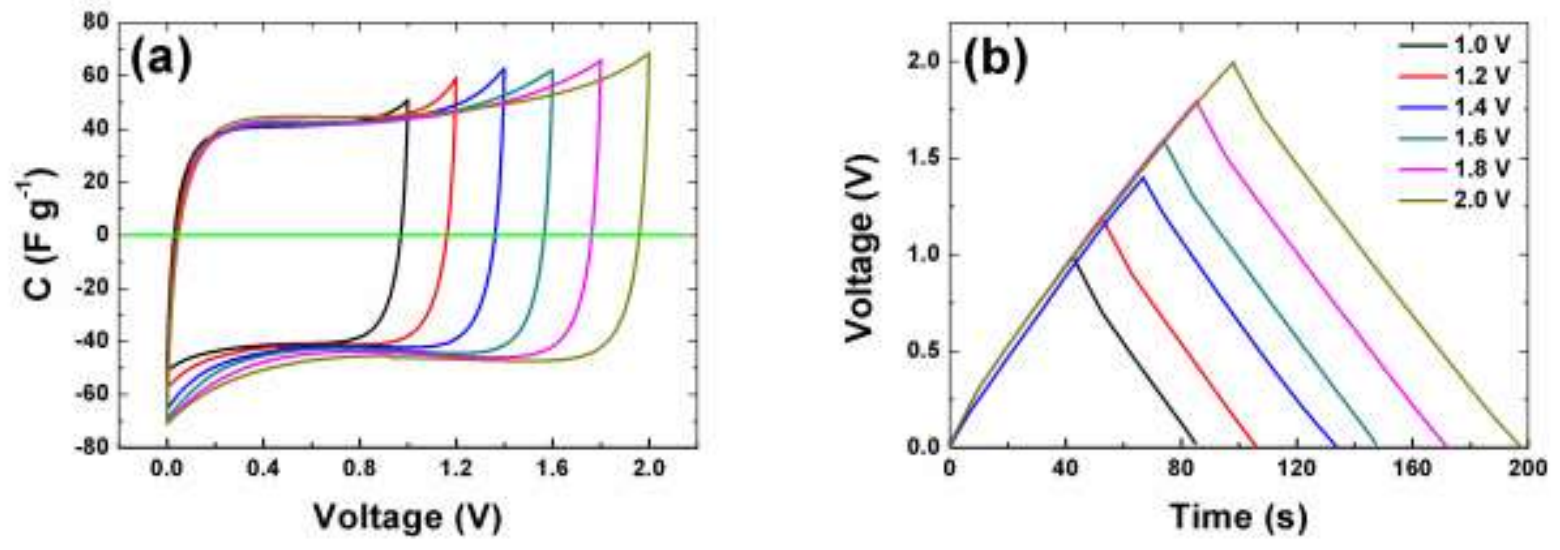

Figure 6 (a) Cyclic voltammogram at $20 \mathrm{mV} \mathrm{s}^{-1}$ and (b) galvanostatic charge-discharge at profiles of the APC at $0.5 \mathrm{~A} \mathrm{~g}^{-1}$ at different voltage ranges respectively.

$\mathrm{CV}$ curves of the APC electrode at $2 \mathrm{~V}$ is shown in Figure 7 (a). The CVs show rectangular shapes characteristic of electrochemical double layer capacitor (EDLC) behavior. As the scan rate increases, the capacitive double layer signature of the electrode is preserved, indicating the porous and polarizable nature of the material. At $100 \mathrm{mV} \mathrm{s}^{-1}, \mathrm{CV}$ demonstrate a resistive $\mathrm{CV}$ shapes that describe the presence of increased ohmic behavior and could be attributed to the decline in capacitance observed in Figure 7 (c). This performance at high scan rates establishes the high power capability of the porous APC material. For quantitative considerations the specific capacitance calculated from the $\mathrm{CV}$ by using the integral area ranges from $98.5 \mathrm{~F} \mathrm{~g}^{-1}$ (10 $\left.\mathrm{mV} \mathrm{s}^{-1}\right)$ to $80 \mathrm{~F} \mathrm{~g}^{-1}\left(100 \mathrm{mV} \mathrm{s}^{-1}\right)$. Essentially the result obtained is attributable to the large 
accessible surface area achieved by good micropore volume and interconnected conducting mesopores pathways. Secondly, the presence of the functional groups present in the sample as observed from the XPS results might lead to a faradaic reaction contributing to the total capacitance of the carbon electrode. Lastly the individual properties of the electrolyte such as hydrated ion size ( $3.58 \AA$ ) which is similar to the PSD and ionic conductivity $50.11 \mathrm{~S} \mathrm{~cm}^{2} \mathrm{~mol}^{-1}$ all contributed to the capacitive properties of the activated carbon electrode ${ }^{52}$. Galvanostatic charge/discharge measurements were applied at different current densities to evaluate the capacitance performance and the result is shown in Figure 7 (b). A symmetric triangular charge and discharge profile distinctive for ideal capacitor was observed, indicating the reversible adsorption/desorption of ions. The gravimetric capacitance was calculated from these curves according to equation 1 and it is shown in Figure 7 (c). Figure 7 (c) shows that the specific capacitance of the sample decreases slightly with increase in current density, suggesting good rate capability. The specific capacitance at $0.1 \mathrm{~A} \mathrm{~g}^{-1}$ is about $137 \mathrm{~F} \mathrm{~g}^{-1}$ and still remains at about $100 \mathrm{~F} \mathrm{~g}^{-1}$ at a current density $5 \mathrm{~A} \mathrm{~g}^{-1}$. Figure 7 (d) shows the Ragone plot which emphasizes the energy-power characteristic of the device. The energy and power densities of $19 \mathrm{Wh} \mathrm{kg}^{-1}$ and $100 \mathrm{~W} \mathrm{~kg}^{-1}$ were obtained respectively for this device. More specifically, compared to previously reported supercapacitors from biomass materials as shown in table 1, our material show a reasonably higher SSA value with good distribution of micro- and mesopore volumes which greatly benefited the electrochemical performance (energy density of $19 \mathrm{Wh} \mathrm{kg}^{-1}$ ) by having easy accessible SSA and reaction sites in aqueous electrolyte which is user friendly compared to most organic electrolytes. Similarly, the pine cones were also carbonized at $700{ }^{\circ} \mathrm{C}$ and $900{ }^{\circ} \mathrm{C}$ to see the effect of activation temperature on the samples and the result is present in the 
supporting information. However, these samples showed very low electrochemical performance, demonstrating highly resistive CV shapes at a voltage of $1 \mathrm{~V}$ (Figure S1). This low performance was related to the pore texture which exhibited a type II $\mathrm{N}_{2}$ isotherm with $\mathrm{H} 2$ and $\mathrm{H} 3$ hysteresis loop for $\mathrm{APC}-900{ }^{\circ} \mathrm{C}$ and $\mathrm{APC}-700{ }^{\circ} \mathrm{C}$ respectively (Figure S2). Signaling a complex pore or non-rigid aggregates structure of sigmoid or macroporous which are not beneficial for high electrochemical performance, since it has been established that the volume of active micropores present in the material ( $<2 \mathrm{~nm}$ in size) acts as ion traps for energy storage and power delivery, mesopores $(2-50 \mathrm{~nm})$ provides the pathways for ion transport and the macropores (> $50 \mathrm{~nm}$ in size) playing the role of an ion buffering reservoir ${ }^{53}$. These results further confirms and demonstrate that activation of material using $\mathrm{KOH}$ and carbonization 800 ${ }^{\circ} \mathrm{C}$ yields the optimum micropore volume in carbon materials for electrochemical energy storage ${ }^{54}$.

In addition to the excellent rate capability of this material, long cycling stability test was conducted under a constant charge at a current density of $5 \mathrm{~A} \mathrm{~g}^{-1}$ for 10,000 cycles. Figure 7 (e) shows the $\varepsilon$ and gravimetric capacitance of the symmetric cell. The capacitance retention was almost $100 \%$ retention; no notable degradation in capacitance value was observed rather there were fluctuations in the $\varepsilon$ plot between 2000 and 4000 cycles after which the $\varepsilon$ was stable. Cycling test based on floating was further used to investigate the long-term stability ${ }^{63}$. Figure 7 (f) shows the stability during voltage-holding over $100 \mathrm{~h}$. Floating at $2 \mathrm{~V}$ has a significant impact 
Table 1 Performance comparison of biomass carbon derived electrodes

\begin{tabular}{|c|c|c|c|c|c|c|c|c|}
\hline $\begin{array}{c}\text { Source of } \\
\text { electrode } \\
\text { material }\end{array}$ & $\begin{array}{l}\text { Activation } \\
\text { agent }\end{array}$ & $\begin{array}{c}S_{\mathrm{BET}} \\
\left(\mathrm{m}^{2} \mathrm{~g}^{-1}\right)\end{array}$ & Electrolyte & $\begin{array}{l}\text { Potential } \\
\text { (V) }\end{array}$ & $\begin{array}{c}\text { Capacitance } \\
\qquad\left(\mathrm{F} \mathrm{g}^{-1}\right)\end{array}$ & $\begin{array}{l}\text { Energy } \\
\text { density } \\
\left(\mathrm{Wh} \mathrm{kg}^{-1}\right)\end{array}$ & $\begin{array}{l}\text { Power density } \\
\qquad\left(\mathrm{W} \mathrm{kg}^{-1}\right)\end{array}$ & Ref. \\
\hline Waste tires & $\begin{array}{c}\mathrm{KOH} \\
\mathrm{H}_{3} \mathrm{PO}_{4}\end{array}$ & $\begin{array}{l}1625 \\
563\end{array}$ & $\begin{array}{l}1 \mathrm{M} \mathrm{H}_{2} \mathrm{SO}_{4} \\
6 \mathrm{M} \mathrm{KOH}\end{array}$ & $\begin{array}{c}0.75 \\
1\end{array}$ & $\begin{array}{l}135^{\mathrm{a}} \\
106^{\mathrm{a}}\end{array}$ & - & - & $\begin{array}{l}55 \\
56\end{array}$ \\
\hline Pomelo peel & - & 2105 & $\begin{array}{c}1 \mathrm{M} \\
\mathrm{NaNO}_{3}\end{array}$ & 1.7 & $43.5^{b}$ & 17.1 & 420 & 57 \\
\hline Human hair & $\mathrm{KOH}$ & 1306 & $\begin{array}{l}1 \mathrm{M} \mathrm{LiPF}_{6} / \\
\mathrm{EC} / \mathrm{DEC}\end{array}$ & 3 & $126^{b}$ & 45.33 & - & 36 \\
\hline $\begin{array}{l}\text { self-adhesive } \\
\text { carbon grains } \\
\text { (SACG) }\end{array}$ & $\mathrm{KOH}$ & 1704 & $6 \mathrm{M} \mathrm{KOH}$ & 1.6 & $150^{b}$ & 4.297 & 173 & 58 \\
\hline $\begin{array}{l}\text { pine cone } \\
\text { petals }\end{array}$ & $\mathrm{KOH}$ & 3950 & $1 \mathrm{M} \mathrm{LiPF_{6 }}$ & 3 & $142^{b}$ & $\sim 61$ & - & 43 \\
\hline $\begin{array}{l}\text { Pistachio } \\
\text { nutshells }\end{array}$ & $\mathrm{KOH}$ & 1069 & $\begin{array}{c}6 \mathrm{M} \mathrm{KOH} \\
1 \mathrm{M} \\
\text { TEABF4 }\end{array}$ & 1.1 & $\begin{array}{c}261^{b} \\
29.3 / 20.1\end{array}$ & $\begin{array}{l}10 \\
39\end{array}$ & $\begin{array}{l}52 \\
286\end{array}$ & 28 \\
\hline Banana Fibers & $\begin{array}{c}\mathrm{ZnCl}_{2} \& \\
\mathrm{KOH}\end{array}$ & 1097 & $\begin{array}{c}1 \mathrm{M} \\
\mathrm{Na}_{2} \mathrm{SO}_{4}\end{array}$ & 1 & $74^{b}$ & - & - & 59 \\
\hline Oil palm EFB & - & 802 & $1 \mathrm{M} \mathrm{H}_{2} \mathrm{SO}_{4}$ & 1 & $196^{b}$ & 5.45 & 236 & 60 \\
\hline $\begin{array}{c}\text { sunflower seed } \\
\text { shell }\end{array}$ & $\mathrm{KOH}$ & 2584 & $3 \mathrm{M} \mathrm{KOH}$ & 0.9 & $311^{b}$ & 4.8 & 240 & 30 \\
\hline Rice husk & $\begin{array}{c}\mathrm{NaOH} \& \\
\mathrm{KOH}\end{array}$ & 2721 & $3 \mathrm{M} \mathrm{KCl}$ & 0.6 & $210^{b}$ & & & 61 \\
\hline Cypress & & 1283 & $1 \mathrm{M} \mathrm{H}_{2} \mathrm{SO}_{4}$ & 1 & $190^{\mathrm{a}}$ & - & - & 31 \\
\hline $\begin{array}{c}\text { Sugar cane } \\
\text { bagasse }\end{array}$ & $\mathrm{ZnCl}_{2}$ & 1788 & $1 \mathrm{M} \mathrm{H}_{2} \mathrm{SO}_{4}$ & 1 & $300^{b}$ & 10 & - & 62 \\
\hline Pine cone & $\mathrm{KOH}$ & 1160.3 & $\begin{array}{c}1 \mathrm{M} \\
\mathrm{Na}_{2} \mathrm{SO}_{4}\end{array}$ & 2 & $137^{b}$ & 19 & 100 & $\begin{array}{l}\text { This } \\
\text { work- }\end{array}$ \\
\hline
\end{tabular}

${ }^{\mathrm{a}}$ Three electrode measurements, ${ }^{\mathrm{b}} \mathrm{Two}$ electrode measurements 

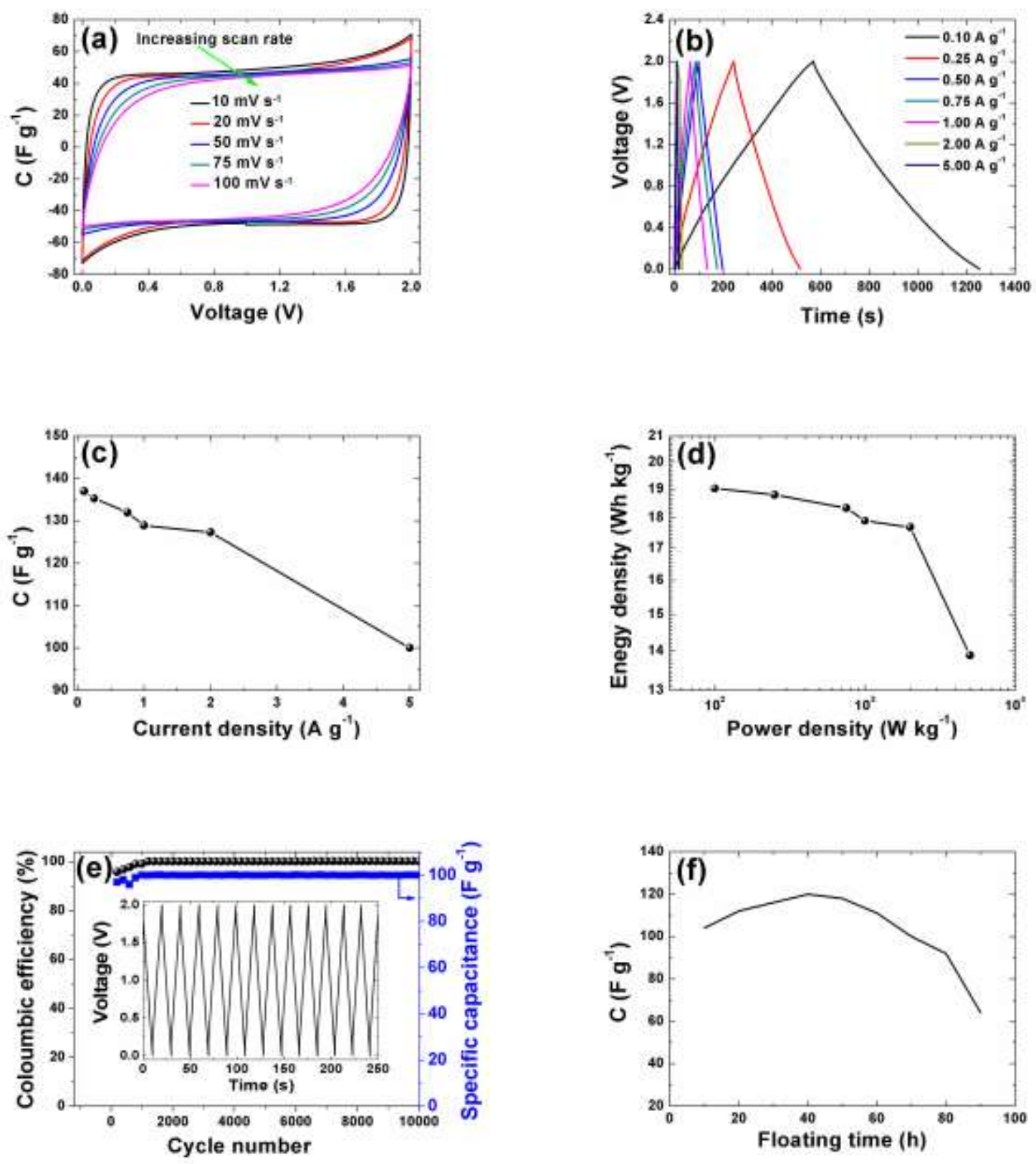

Figure 7 Electrochemical performances tests for the APC in $1 \mathrm{M} \mathrm{Na}_{2} \mathrm{SO}_{4}$ aqueous electrolyte: (a) CV curves at different scan rates, (b) CD curves at different current densities, (c) dependence of specific capacitance on current density, (d) Ragone plot (e) Coulombic efficiency and gravimetric capacitance vs. cycle number and (f) $100 \mathrm{~h}$ voltage holding vs. capacitance. 
on the capacitance which slowly increases during the ageing time. As observed from the figure there was a rapid increase in the capacitance to about $120 \mathrm{~F} \mathrm{~g}^{-1}$ before starting to show decay. The increase in capacitance we attribute to the expansion and swelling of the APC porous structure during the ageing time thus creating more accessible surface for adsorption of ion from the electrolyte hence increasing the capacitance of the cell. Most importantly the specific capacitance was still $\sim 60 \mathrm{~F} \mathrm{~g}^{-1}$ after holding for $100 \mathrm{~h}$. Such excellent cycling stability is attributed to the structural properties with a relatively high pore volume and robust network preventing crumbling or disintegration of the porous structure.

Electrochemical impedance spectroscopy was used to study the ion transport mechanism and further to demonstrate the performance of the APC-based symmetric supercapacitors. Figure 8 (a) shows the Nyquist plot with a nearly straight line in the low-frequency region and an arc in the high-frequency region indicating a distinct capacitive behavior of porous carbon electrodes. The arc in the high frequency region is related to charge transport phenomena $\left(R_{C T}\right)$. From the high frequency range data analysis, the ohmic resistance $\left(R_{S}\right)$ was estimated. $R_{S}$ includes the intrinsic resistance of the electrode materials, the electrolyte, and the contact resistance between the interfaces of electrodes, electrolyte, and current collector ${ }^{64}$. The inset of Figure 8 (a) shows the magnified high frequency region showing the $R_{S}$ value of $1.5 \Omega$ and the corresponding $R_{C T}$ was measured at the diameter of the arc as $1.9 \Omega$. This $R_{C T}$ value is related to the morphology of the APC electrode material facilitating a rapid charge transfer process. The Nyquist plot before and after cycling is shown in Figure S3. From the Figure, an increase in the $R_{S}$ value was observed while a decrease in $R_{C T}$ was also observed. The increase in $R_{S}$ could be 
due to the formation of inactive sites caused by the partial collapse of the three dimensional structure during the cycle test.

The fitting of the Nyquist spectrum was performed by a modified Randles circuit with a set of resistors and capacitors in series and parallel using a fitting program ZFIT/EC-Lab version 10.40 and is represented in Figure 8 (b) with the equivalent circuit shown in the inset. The semicircle in the high-mid frequency region is represented by the charge transfer resistance $R_{C T}$ and the interface contact capacitance $C_{1}$ between the active material and current collector are connected parallel to each other and are in series with $R_{S}$. The $R_{C T}$ is connected in series with a constant phase element $Q$ that account for the double-layer capacitance and is associated with a Faradaic resistance $R_{3}$. Ideally, if there is no diffusion resistance at very low frequencies, an ideal polarizable capacitive electrode would lead to a vertical line parallel to vertical axis (-Z") with a mass capacitance represented as $C_{2}$. However, from the Nyquist plot there is a deviation from this ideal behavior. This deviation is attributed to the existence of a resistive element associated with $\mathrm{C}_{2}$. This resistance can be designated as diffusion resistance or leakage resistance $R_{4}$ and is in parallel to $C_{2}$. The fitting parameters are shown in table $S 3$ (supporting information) and values obtained are approximately within the experimental data suggesting that model used for fitting was correct with an error of $0.005 . X^{2}$ represents the criterion for minimization of the fit. $\mathrm{X} / \sqrt{N}$ where $\mathrm{N}$ is the number of points. 

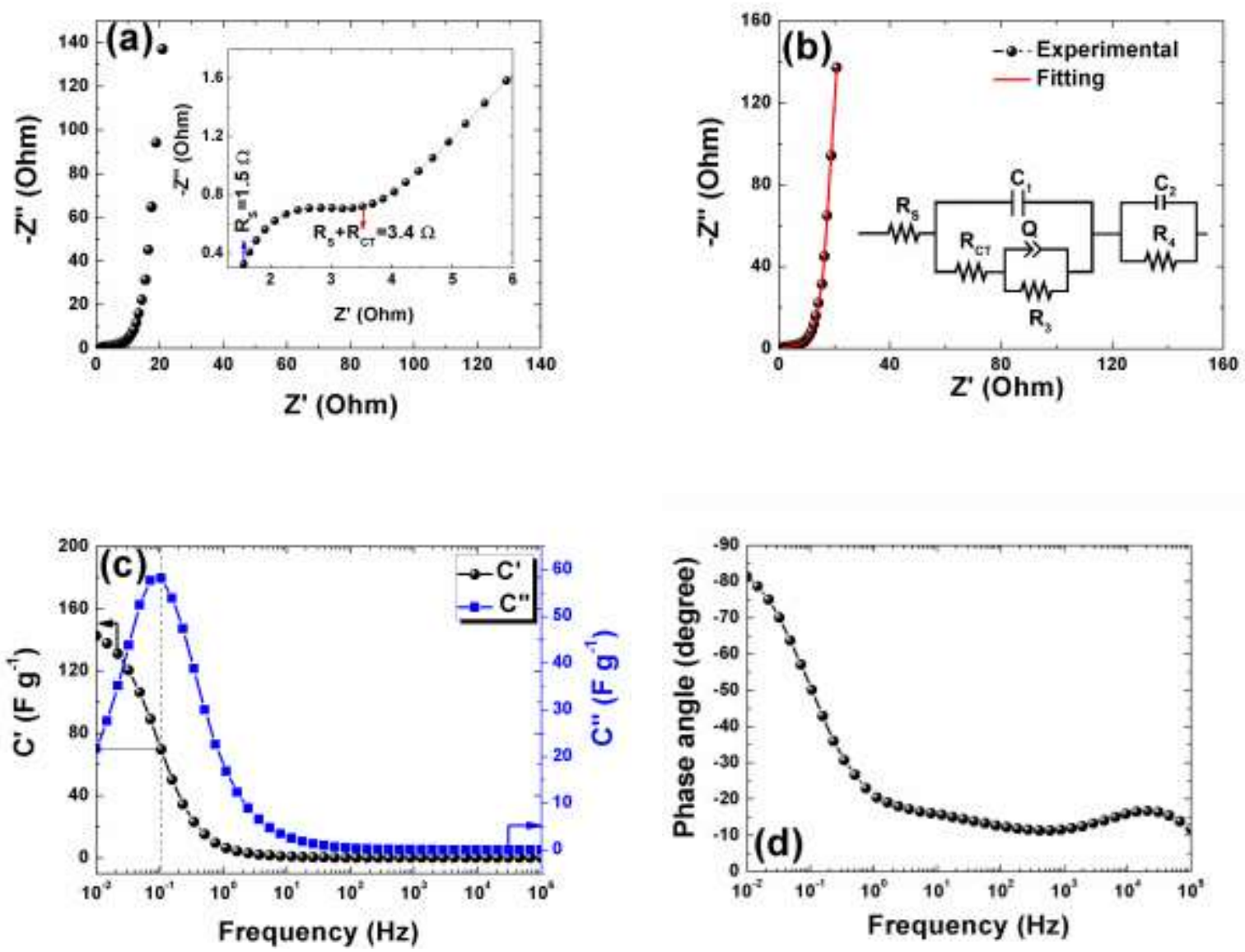

Figure 8 (a) and (b) Nyquist plots for the APC based cell in $1 \mathrm{M} \mathrm{Na}_{2} \mathrm{SO}_{4}$ with magnifications of the high to mid frequency region shown in the inset and fitted with equivalent circuit shown in the inset respectively, (c) the real and imaginary part of the cell gravimetric capacitance vs. frequency (black and blue curves) (d) Bode plot for the phase angle vs. frequency.

A complex capacitance model based on the single RC time-constant was used to characterize both real part $C^{\prime}(\omega)$ and imaginary part $C^{\prime \prime}(\omega)$ capacitance as function of the frequency, to investigate the frequency behavior and also estimate the relaxation time constant of porous electrodes ${ }^{46}$. Figure 8 (c) show the real and imaginary part of the capacitance with frequency of 
the APC cell, the corresponding capacitance from this graph is $143 \mathrm{~F} \mathrm{~g}^{-1}$ (from topmost part of the black curve) which is comparable to the results obtained from the CD measurements. This demonstrates the fast frequency response of the porous carbon material in aqueous solution with good capacitance, retention and high power delivery. The imaginary part of the capacitance (the blue curve) corresponds to the energy dispersion. The peak at $0.1 \mathrm{~Hz}$ was used to estimate the relaxation time $(\tau)$, calculated from $\tau=1 / \omega_{\max }=1 /\left(2 \pi f_{\max }\right)$ where $f_{\max }$ is the characteristic frequency of the cell obtained at the phase angle of $-45^{\circ}$ corresponding to the time between the capacitive and resistive behavior of the supercapacitor electrode ${ }^{46}$. A relaxation time of $\sim 9.5 \mathrm{~s}$ was obtained indicating that the stored energy can efficiently be delivered within this time. Figure 8 (d) shows the Bode phase plot which indicates that in the low frequency region a phase shift of $\sim-81.3^{\circ}$ close to $-90^{\circ}$ indicating characteristic of the purely capacitive double layer charge storage phenomenon.

\section{Conclusion}

High surface area porous carbon has been successfully synthesized from the abundant and readily available pine cone biomass via $\mathrm{KOH}$ activation and carbonization at $800{ }^{\circ} \mathrm{C}$. Structural and morphological characterizations show that the material exhibit three dimensional porous cavities with a specific surface area of $1515 \mathrm{~m}^{2} \mathrm{~g}^{-1}$. Electrochemical performances of the porous carbon as active materials for supercapacitors were tested in $1 \mathrm{M} \mathrm{Na}_{2} \mathrm{SO}_{4}$ electrolyte. A high voltage window of $2.0 \mathrm{~V}$ was observed for a symmetric carbon/carbon electrodes cell offering good rate capability with a reasonable gravimetric capacitance of $137 \mathrm{~F} \mathrm{~g}^{-1}$, energy density of 19 Wh $\mathrm{kg}^{-1}$ and excellent cyclability. These results in neutral $1 \mathrm{M} \mathrm{Na}_{2} \mathrm{SO}_{4}$ electrolyte are quite 
interesting, encouraging and showed the applicability of pine cones derived carbons, demonstrating the exciting potential for a low-cost porous carbon which could attract interest from the industry for potential application in energy storage, absorbent and catalysis.

\section{Acknowledgment}

"This work is based on the research supported by the South African Research Chairs Initiative of the Department of Science and Technology and National Research Foundation of South Africa (Grant No 97994). Any opinion, finding and conclusion or recommendation expressed in this material is that of the author(s) and the NRF does not accept any liability in this regard". F. Barzegar and D. Y. Momodu acknowledge financial support from the University of Pretoria and the NRF for their PhD bursaries, while A. Bello and A. A. Khaleed acknowledges NRF through SARChl in Carbon Technology and Materials and University of Pretoria for Postdoctoral and PhD financial support. We also thank Prof. Yury Gogotsi's group at Drexel University XPS measurements.

\section{References}

1. P. T. Anastas and J. C. Warner, Green chemistry: theory and practice, Oxford university press, 2000.

2. H. Sun, L. Cao, and L. Lu, Energy Environ. Sci., 2012, 5, 6206-6213.

3. R. C. Saxena, D. K. Adhikari, and H. B. Goyal, Renew. Sustain. Energy Rev., 2009, 13, 167178.

4. A. Faaij, Mitig. Adapt. Strateg. Glob. Chang., 2006, 11, 335-367.

5. K. Sanderson, Nature, 2006, 444, 673-676. 
6. S. E. Koonin, Sci., 2006, 311, 435.

7. R. S. Dhillon and G. von Wuehlisch, Biomass and bioenergy, 2013, 48, 75-89.

8. B. E. Conway, Electrochemical Supercapacitors: Scientific Fundamentals and Technological Applications, Springer, 1999.

9. P. Simon and Y. Gogotsi, Nat. Mater., 2008, 7, 845-854.

10. Y. Zhai, Y. Dou, D. Zhao, P. F. Fulvio, R. T. Mayes, and S. Dai, Adv. Mater., 2011, 23, 482850 .

11. S. Dörfler, I. Felhösi, T. Marek, S. Thieme, H. Althues, L. Nyikos, and S. Kaskel, J. Power Sources, 2013, 227, 218-228.

12. E. Iyyamperumal, S. Wang, and L. Dai, ACS Nano, 2012, 6, 5259-5265.

13. Y. Korenblit, M. Rose, E. Kockrick, L. Borchardt, A. Kvit, S. Kaskel, and G. Yushin, ACS Nano, 2010, 4, 1337-1344.

14. V. Presser, M. Heon, and Y. Gogotsi, Adv. Funct. Mater., 2011, 21, 810-833.

15. P. Simon and Y. Gogotsi, Acc. Chem. Res., 2012, 46, 1094-1103.

16. Y. Gao, Y. S. Zhou, M. Qian, X. N. He, J. Redepenning, P. Goodman, H. M. Li, L. Jiang, and Y. F. Lu, Carbon, 2013, 51, 52-58.

17. B. G. Choi, M. Yang, W. H. Hong, J. W. Choi, and Y. S. Huh, ACS Nano, 2012, 6, 4020-4028.

18. L. L. Zhang, R. Zhou, and X. S. Zhao, J. Mater. Chem., 2010, 20, 5983-5992.

19. J. W. Long, D. Bélanger, T. Brousse, W. Sugimoto, M. B. Sassin, and O. Crosnier, Mrs Bull, $2011,36,513-522$. 
20. M. P. Bichat, E. Raymundo-Piñero, and F. Béguin, Carbon, 2010, 48, 4351-4361.

21. M. Biswal, A. Banerjee, M. Deo, and S. Ogale, Energy Environ. Sci., 2013, 6, 1249-1259.

22. A. Shaikjee and N. J. Coville, Carbon, 2012, 50, 3376-3398.

23. H. Tang, P. Gao, X. Liu, H. Zhu, and Z. Bao, J. Mater. Chem. A, 2014, 2, 15734-15739.

24. E. Raymundo-Piñero, M. Cadek, and F. Béguin, Adv. Funct. Mater., 2009, 19, 1032-1039.

25. H. Wang, Z. Xu, A. Kohandehghan, Z. Li, K. Cui, X. Tan, T. J. Stephenson, C. K. King'ondu, C. M. B. Holt, B. C. Olsen, T. Jin Kwon, D. Harfield, A. Anthony O., Anyia, and M. David, ACS Nano, 2013, 7, 5131-5141.

26. L. Wei, M. Sevilla, A. B. Fuertes, R. Mokaya, and G. Yushin, Adv. Energy Mater., 2011, 1, 356-361.

27. H. Sun, W. He, C. Zong, and L. Lu, ACS Appl. Mater. Interfaces, 2013, 5, 2261-2268.

28. J. Xu, Q. Gao, Y. Zhang, Y. Tan, W. Tian, L. Zhu, and L. Jiang, Sci. Rep., 2014, 4.

29. M. Lee, G.-P. Kim, H. D. Song, S. Park, and J. Yi, Nanotechnology, 2014, 25, 345601.

30. X. Li, W. Xing, S. Zhuo, J. Zhou, F. Li, S.-Z. Qiao, and G.-Q. Lu, Bioresour. Technol., 2011, 102, 1118-1123.

31. E. Ito, S. Mozia, M. Okuda, T. Nakano, M. Toyoda, and M. Inagaki, New Carbon Mater., 2007, 22, 321-326.

32. S. Kumagai, M. Sato, and D. Tashima, Electrochim. Acta, 2013, 114, 617-626.

33. A. R. Mohamed, M. Mohammadi, and G. N. Darzi, Renew. Sustain. Energy Rev., 2010, 14, 1591-1599. 
34. D. Vamvuka, Int. J. Energy Res., 2011, 35, 835-862.

35. Y. Qu, Y. Tian, B. Zou, J. Zhang, Y. Zheng, L. Wang, Y. Li, C. Rong, and Z. Wang, Bioresour. Technol., 2010, 101, 8402-8405.

36. W. Qian, F. Sun, Y. Xu, L. Qiu, C. Liu, S. Wang, and F. Yan, Energy Environ. Sci., 2014, 7, 379-386.

37. N. Ayrilmis, U. Buyuksari, E. Avci, and E. Koc, For. Ecol. Manage., 2009, 259, 65-70.

38. J. A. Micales, J. S. Han, J. L. Davis, and R. A. Young, in Mycotoxins, Wood Decay, Plant Stress, Biocorrosion, and General Biodeterioration, Springer, 1994, pp. 317-332.

39. M. Momčilović, M. Purenović, A. Bojić, A. Zarubica, and M. Randjelović, Desalination, 2011, 276, 53-59.

40. A. Özhan, Ö. Sahin, M. M. Küçük, and C. Saka, Cellulose, 2014, 21, 2457-2467.

41. G. V Nunell, M. E. Fernandez, P. R. Bonelli, and A. L. Cukierman, J. Colloid Interface Sci., 2015, 440, 102-108.

42. A. E. Ofomaja and E. B. Naidoo, Chem. Eng. J., 2011, 175, 260-270.

43. K. Karthikeyan, S. Amaresh, S. N. Lee, X. Sun, V. Aravindan, Y.-G. Lee, and Y. S. Lee, ChemSusChem, 2014, 7, 1435-1442.

44. Y. Zhang, F. Zhang, G.-D. Li, and J.-S. Chen, Mater. Lett., 2007, 61, 5209-5212.

45. J. Wang and S. Kaskel, J. Mater. Chem., 2012, 22, 23710-23725.

46. P. L. Taberna, P. Simon, and J.-F. Fauvarque, J. Electrochem. Soc., 2003, 150, A292-A300.

47. C. Liu, F. Li, L.-P. Ma, and H.-M. Cheng, Adv. Mater., 2010, 22, E28-E62. 
48. A. G. Pandolfo and A. F. Hollenkamp, J. Power Sources, 2006, 157, 11-27.

49. A. C. A. Ferrari, Solid State Commun., 2007, 143, 47-57.

50. K. Fic, G. Lota, M. Meller, and E. Frackowiak, Energy Environ. Sci., 2012, 5, 5842-5850.

51. L. Demarconnay, E. Raymundo-Pinero, and F. Béguin, Electrochem. commun., 2010, 12, 1275-1278.

52. C. Zhong, Y. Deng, W. Hu, J. Qiao, L. Zhang, and J. Zhang, Chem. Soc. Rev., 2015.

53. M. Zhi, F. Yang, F. Meng, M. Li, A. Manivannan, and N. Wu, ACS Sustain. Chem. Eng., 2014.

54. S. Murali, J. R. Potts, S. Stoller, J. Park, M. D. Stoller, L. L. Zhang, Y. Zhu, and R. S. Ruoff, Carbon, 2012, 50, 3482-3485.

55. M. Boota, M. P. Paranthaman, A. K. Naskar, Y. Li, K. Akato, and Y. Gogotsi, ChemSusChem, 2015.

56. M. Zhi, F. Yang, F. Meng, M. Li, A. Manivannan, and N. Wu, ACS Sustain. Chem. Eng., 2014, 2, 1592-1598.

57. C. Peng, J. Lang, S. Xu, and X. Wang, RSC Adv., 2014, 4, 54662-54667.

58. R. Farma, M. Deraman, A. Awitdrus, I. A. Talib, E. Taer, N. H. Basri, J. G. Manjunatha, M. M. Ishak, B. N. M. Dollah, and S. A. Hashmi, Bioresour. Technol., 2013, 132, 254-261.

59. V. Subramanian, C. Luo, A. M. Stephan, K. S. Nahm, S. Thomas, and B. Wei, J. Phys. Chem. C, 2007, 111, 7527-7531.

60. N. S. M. Nor, M. Deraman, R. Omar, R. Farma, N. H. Basri, B. N. M. Dolah, N. F. Mamat, B. Yatim, M. N. M. Daud, and others, Energy, 2015, 79, 183-194. 
61. Y. Guo, J. Qi, Y. Jiang, S. Yang, Z. Wang, and H. Xu, Mater. Chem. Phys., 2003, 80, 704709.

62. T. E. Rufford, D. Hulicova-Jurcakova, K. Khosla, Z. Zhu, and G. Q. Lu, J. Power Sources, 2010, 195, 912-918.

63. P. Ratajczak, K. Jurewicz, and F. Béguin, J. Appl. Electrochem., 2014, 44, 475-480.

64. J. Luo, H. D. Jang, and J. Huang, ACS Nano, 2013, 7, 1464-1471. 